\title{
Knowledge, attitude, and practice of healthcare professionals regarding infection prevention at Gondar University referral hospital, northwest Ethiopia: a cross-sectional study
}

\author{
Teshiwal Deress Yazie ${ }^{1 *} \mathbb{0}$, Gezahegn Bewket Sharew² and Wondwossen Abebe ${ }^{3}$
}

\begin{abstract}
Objectives: Workplace health and safety is vital in every organization particularly in the healthcare settings. The aim was to assess the levels of knowledge, attitude, and practices of the healthcare professionals towards safety at Gondar University referral hospital. An institution based cross-sectional study was conducted from February to June 2018. Proportional random sampling technique was used to include 282 study participants and data were collected using a structured self-administered questionnaire and analyzed using SPSS version 20.

Results: Among 282 study participants, 230 (81.6\%), 181 (64.2\%), and 162 (57.4\%) had adequate knowledge, favorable attitude, and adequate practice scores, respectively. More than half (55.3\%) of the study participants were untrained. There was a high (26.6\%) prevalence of needlestick injury; however, the use of post-exposure prophylaxis after potential exposures was very limited. Generally, the levels of knowledge, attitude, and practice scores among the study participants were low. Therefore, there should be adequate and consistent supply of personal protective devices and other materials used for infection prevention and control. In addition, there should be awareness raising mechanism, including the provision of job aids and periodic training. Further, comprehensive studies should be conducted by including different types and levels of health facilities.
\end{abstract}

Keywords: Healthcare professional, Knowledge, Attitude, Practice, Safety, Ethiopia

\section{Introduction}

Workplace health and safety is a critical element in every organization particularly in the healthcare settings [1]. Healthcare professionals (HCPs) may act as a mechanical vector for the transmission of nosocomial infections from patient to patient [2,3]. Accidental exposure to body fluids can cause bloodborne infections particularly hepatitis $B$ virus (HBV), human immunodeficiency virus (HIV),

\footnotetext{
*Correspondence: teshiwalderess@gmail.com; teshiwal.deress@uog.edu.et

${ }^{1}$ Unit of Quality Assurance and Laboratory Management, School of Biomedical and Laboratory Sciences, College of Medicine and Health Sciences, University of Gondar, P. O. Box 196, Gondar, Ethiopia Full list of author information is available at the end of the article
}

and hepatitis $\mathrm{C}$ virus (HCV) [4]. Exposures may happen through needlestick or sharp injuries contaminated with infected body fluids or through contact with splashes [5]. The risk of seroconversion after percutaneous exposure to infected blood is approximately $0.1-0.3 \%$ for HIV, $2 \%$ for $\mathrm{HCV}$, and 6-60\% for HBV [4]. Safety practices help to protect healthcare workers, patients, and visitors from health hazards [6-8]. It includes the use of personal protective equipment (PPE) including gloves, gowns, eye goggles, aprons, masks [7], and through the provision of professional immunization programs [9]. With inadequate infection prevention practice, the risk of acquiring infections through exposure to body fluids is substantial [10]. 
Infection is one of the most important challenges in the healthcare facilities worldwide. It constituted the morbidity and mortality among the exposed groups [11]. All individuals particularly HCPs are potentially at high risk of infection due to their frequent exposure to body fluids [12-18]. Lack of proper protective devices and the absence of enabling working environment lead to poor compliance of safety precautions [19]. Hospital-acquired infections are the main problems associated with the healthcare services $[20,21]$ and currently, more than 1.4 million people are suffering from hospital-acquired infections worldwide and the risk is 2-20 times higher among the developing countries [22-24]. The World Health Organization (WHO) estimated that about 3 million healthcare workers are exposed to bloodborne viruses each year. Among this, about $90 \%$ of the infections were occurred in the developing countries [15].

The associated burden of disease related to hospitalacquired infections is prolonged hospital stay, long-term disability, increased microbial resistance, financial burden and deaths $[3,25,26]$. Although safety is an important component of the quality health services, currently there is limited information available regarding the level of knowledge, attitude and practice among the HCPs in the study area. Therefore, this study was aimed to assess the levels of knowledge, attitude, and practice scores of the HCPs towards safety at Gondar University referral hospital. The study will help policymakers in design and development of the appropriate infection prevention programs, and strategic plans.

\section{Main text \\ Methods \\ Study design and setting}

An institution based cross-sectional study was conducted from February to June 2018 at Gondar University referral hospital. The hospital is found in Gondar town at $748 \mathrm{~km}$ far from Addis Ababa, a capital city of Ethiopia, to the northwest. It is a multidisciplinary specialized teaching hospital with 550 inpatient beds. Currently, it provides health services to more than 5 million inhabitants in its catchment area [27]. According to the hospital human resource report, during 2018 there were 902 registered fulltime employee HCPs from which 86, 483, 95, and 110 were medical doctors, nurses, midwives, and medical laboratory professionals, respectively.

\section{Sample size, sampling technique, and eligibility}

The sample size was determined using a single population proportion formula. The final sample size was estimated to be 282 including 10\% nonresponse rates. Proportional random sampling technique was used to include 282 study participants in the study. Only full-time employee
HCPs who were potentially at high-risk (medical doctors, medical laboratory technologists, nurses, and midwives), available during the data collection period and consented to take part in the study were included.

\section{Data collection and quality control}

A structured self-administered questionnaire was used to collect the data. The questionnaire was developed after a review of the available scientific papers in the subject area [27-32]. Four main sections (socio-demographic characteristics, knowledge, attitude, and practice) were included in the data collection tool (Additional file 1). The tool was pretested on $10 \%$ of the similar study population and then the contents were slightly modified and suggestions from different experts were included. After training was provided, three medical laboratory professionals were involved in the data collection process and the medium of instruction was English. Information sheet and consent forms were included in the first part of the questionnaire. The questionnaire was distributed to the study participants in the form of hard copies. Then study participants were requested to read the informedconsent statements before they proceed to the next section. Study participants who unwilling to take part in the study were asked to return questionnaires to the data collectors. The questionnaires were collected, checked for completeness and any incomplete questionnaire was taken back to the respondent for completion. In addition, timely supervision of the data collection process was done by the investigators. Further, the data were tested statistically for internal consistency (reliability) using Cronbach's alpha test. The overall Cronbach's alpha value was 0.695 which indicates that the items are somewhat inter-related.

\section{Methods of measurement and analysis}

Data were coded and entered into Epi info version 3.5.1 software and exported into SPSS version 20 for analysis. Knowledge and practice questions were scored as 1 or 0 for correct and incorrect responses, respectively. Whereas, attitude responses were provided 1, 2, or 3 for "Disagree", "Neutral" and "Agree", respectively. Summary statistics such as frequencies and proportions were computed as appropriate. Mean scores were calculated and used as a cut point to dichotomize the outcome variables. Scores below the mean scores were considered as inadequate knowledge, unfavorable attitude, or inadequate practice; whereas, scores equal to the mean score or above were considered as adequate knowledge, favorable attitude, or adequate practice. The cut-off value for the knowledge, attitude, and practice scores were adapted from similar studies [33-36]. 


\section{Ethical considerations}

Ethical clearance and support letters were obtained from the Ethical Review Committee (ERC) of the School of Biomedical and Laboratory Sciences, University of Gondar. The support letter was submitted to the Gondar University referral hospital. Then, permission was obtained from the hospital director and department/ section heads. Study participants were informed about the purpose and importance of the study through written informed concent before the data collection process. In addition, participants who were unwilling to take part in the study and those who need to quit their participation at any stage were informed to do so without any restriction.

\section{Results}

\section{Socio-demographic characteristics}

Among 282 study participants, 143 (50.7\%) were male and the age was ranged from 23 to 53 years. Concerning their job categories, 176 (62.4\%), 31 (11\%), 40 (14.2\%), and $35(12.4 \%)$ were nurses, doctors, laboratorians, and midwives, respectively. About 73 (25.9\%), 62 (22\%), and $147(52.1 \%)$ had $\leq 2$ years, $3-4$ years, and $\geq 5$ years of work experience, respectively. Most study participants (83.7\%) were first-degree holders. Only $126(44.7 \%)$ of them were taken training regarding infection prevention and safety. The majority (86.5\%) of the participants were vaccinated for HBV (Table 1).

\section{Knowledge of study participants}

In this study, the mean knowledge score of the study participants was 10.69. Among 282 study participants, 230 $(81.6 \%)$ of them had adequate knowledge score. About $230(81.6 \%)$ of them correctly identified that a safety box should be filled only a maximum of three-fourth. Similarly, $231(81.9 \%)$ of the study participants knew that 72 is the maximum time delay to start HIV post-exposure prophylaxis. Additional findings on the knowledge scores is attached as an Additional file 2.

\section{Attitude of study participants}

The mean attitude score of the study participants was 9.65. Based on this cutoff value 181 (64.2\%), and 101 (35.8) of the study participants had favorable and unfavorable attitude scores, respectively. Almost all the study participants $280(99.3 \%)$ respond that safety precaution

Table 1 Showing socio-demographic and health facility related characteristics for the evaluation of safety precaution in Gondar University referral hospital, Northwest Ethiopia, 2018

\begin{tabular}{|c|c|c|}
\hline Socio-demographic and $\mathrm{HC}$ related variables & Variable category & Frequency $\mathrm{n}(\%)$ \\
\hline \multirow[t]{3}{*}{ Age group } & $\leq 25$ years & $26(9.2 \%)$ \\
\hline & $26-30$ years & $166(58.9 \%)$ \\
\hline & $\geq 31$ years & $90(31.9 \%)$ \\
\hline \multirow[t]{5}{*}{ Working department } & OPD & $60(21.3 \%)$ \\
\hline & Ward & $139(49.3 \%)$ \\
\hline & Laboratory & $32(11.3 \%)$ \\
\hline & Emergency & $24(8.5 \%)$ \\
\hline & Others & $27(9.6 \%)$ \\
\hline \multirow[t]{2}{*}{ Working hours per day } & $8 \mathrm{~h}$ & $180(63.8 \%)$ \\
\hline & More than $8 \mathrm{~h}$ & $102(36.2 \%)$ \\
\hline \multirow[t]{3}{*}{ Number of study participants by the dose of HBV vaccine they completed } & First dose & $12(4.3 \%)$ \\
\hline & Second dose & $40(14.2 \%)$ \\
\hline & Third dose & $190(67.4 \%)$ \\
\hline \multirow[t]{3}{*}{ Availability of sufficient quantity PPE in the department } & Yes & $118(41.8 \%)$ \\
\hline & No & $139(49.3 \%)$ \\
\hline & Not sure & $25(8.9 \%)$ \\
\hline \multirow[t]{3}{*}{ Availability of safety guidelines/manuals in the department/section } & Yes & $135(47.9 \%)$ \\
\hline & No & $118(41.8 \%)$ \\
\hline & Not sure & $29(10.3 \%)$ \\
\hline \multirow[t]{4}{*}{ Source of information about safety precaution } & Training & $57(20.2 \%)$ \\
\hline & Guideline & $129(45.7 \%)$ \\
\hline & Friend & $63(22.3 \%)$ \\
\hline & Others & $33(11.7 \%)$ \\
\hline
\end{tabular}


is important for the healthcare facilities. Similarly, 272 (96.5\%) of the study participants believed that healthcare workers are potentially at risk of infection (Table 2).

\section{Practice of study participants}

The mean and adequate practice scores of the study participants were 7.65 and 162 (57.4\%), respectively. Regarding previous exposure to biohazards, about one-fourth (26.6\%) of the study participants were encountered needlestick/sharps injuries during the previous 12 months preceding the data collection period. Among them, only 49 (17.4\%) had taken HIV post-exposure prophylaxis. Regarding mobile phone usage during their professional practice, about one-third (33\%) of the study participants responded that they have always answered their phones with glove hands. With respect to segregation of healthcare wastes, $219(77.7 \%)$ of them segregated according to their type (Table 3).

\section{Discussion}

Safety is an important component of every healthcare organization which enables to provide quality health services and essential to protect health workers, patients, and community from health-related risks. Particularly, exposure to body fluids containing infectious agents has long been recognized as a potential threat to the HCPs. The current study showed that $81.6 \%$ of the study participants had adequate knowledge score regarding safety precautions. This finding is more or less comparable to $84 \%$ and $84.7 \%$ findings from the health institutions of Bahir Dar and Debre Markos town, respectively [37, 38]. This result was better than $50 \%$ a finding from Nigeria [39]. The possible explanation for the difference could be due to a difference in methodology, educational level, work experience, training opportunity, and personal characteristics of the study participants between the countries.

Table 2 Frequency of study participants among each Likert type of variables at Gondar University referral hospital, Northwest Ethiopia, 2018

\begin{tabular}{|c|c|c|c|}
\hline \multirow[t]{2}{*}{ Variables } & \multicolumn{3}{|l|}{ Response } \\
\hline & Agree $\mathrm{n}(\%)$ & Disagree $\mathrm{n}(\%)$ & Neutral n (\%) \\
\hline Occupational safety training is important for health professionals & $274(97.2)$ & $6(2.1)$ & $2(0.7)$ \\
\hline Healthcare environments can expose HCPs to a health hazard & $260(92.2)$ & $15(5.3)$ & $7(2.5)$ \\
\hline HCPs workplace related risk exposure is a major crisis & $213(75.5)$ & $42(14.9)$ & $27(9.6)$ \\
\hline Workplace risk assessment is important for occupational safety & $279(98.9)$ & $2(0.7)$ & $1(0.4)$ \\
\hline Sharp materials should be discarded in a safety box & $278(98.6)$ & $3(1.1)$ & $1(0.4)$ \\
\hline Needles should be recapped before disposal & $103(36.5)$ & $167(59.2)$ & $12(4.3)$ \\
\hline Wearing PPE during the healthcare delivery process is mandatory & $251(89)$ & $23(8.2)$ & $8(2.8)$ \\
\hline Vaccination of healthcare workers is necessary & $263(93.3)$ & $17(6.0)$ & $2(0.7)$ \\
\hline HBV can be transmitted through biomedical wastes & $248(93.3)$ & $17(6.0)$ & $2(0.7)$ \\
\hline
\end{tabular}

Table 3 Frequency of the study participants among safety practice-related variables at Gondar University referral hospital, Northwest Ethiopia, 2018

\begin{tabular}{|c|c|c|c|}
\hline \multirow[t]{2}{*}{ Variables } & \multicolumn{3}{|l|}{ Response } \\
\hline & Always n (\%) & Sometimes n (\%) & Not at all $n(\%)$ \\
\hline Use safety guideline/manual at the workplace & $67(23.8)$ & $143(50.7)$ & $72(25.5)$ \\
\hline Wear gloves during risky procedures & $280(88.7)$ & $32(11.3)$ & 0 \\
\hline Wash hands with detergent after contact with patients & $155(55)$ & $122(43.3)$ & $5(1.8)$ \\
\hline Use of PPE during professional practice & $149(52.8)$ & $122(44.3)$ & $8(2.8)$ \\
\hline Clean working environment at the end of the working time & $138(48.9)$ & $130(46.1)$ & $14(5)$ \\
\hline Monitor working environment waste management system & $116(41.1)$ & $135(47.9)$ & $13(4.6)$ \\
\hline Changing gloves between patients & $182(64.5)$ & $89(31.6)$ & $11(3.9)$ \\
\hline Wash hands after removal of gloves & $146(51.8)$ & $131(46.5)$ & $5(1.8)$ \\
\hline Recap used needles before disposal & $101(35.8)$ & $54(19.8)$ & $127(45)$ \\
\hline Treat infectious wastes with appropriate disinfectants & $180(63.8)$ & $73(25.9)$ & $29(10.3)$ \\
\hline
\end{tabular}

PPE personal protective equipment 
When each of the specific components of safety precautions was analyzed, better results have been obtained in some items. For instance, a relatively high proportion of HCPs have awareness on the transmission mechanisms of infectious agents (98.6\%), proper handling of used needles and sharps (98.9\%), and importance of wearing PPE during the clinical practices (95.7\%). On the other hand, about $81.6 \%$ of study participants aware that only a maximum three-fourth of the safety box should be filed to prevent needle stick injuries which were quite unsatisfactory. Regarding HCPs awareness on the potential risks of their working environment, $89 \%$ of them aware that they were working in a risk full environment which is relatively quite satisfactory. On the other hand, only $77.3 \%$ of them aware of how to perform work environment risk assessment. With respect to the segregation of medical wastes, only $81.6 \%$ of them had awareness of separation of wastes according to their type before disposal. This means that about $18 \%$ HCPs may probably dispose of wastes randomly in any waste container and this malpractice may increase the amount of biologically hazardous waste generated from the healthcare facilities. This is because when the infectious waste type is mixed with the general waste type then the entire mass will be unnecessarily polluted.

With respect to study participants' attitude, unacceptably low (64.2\%) number of study participants had favorable attitude score regarding safety precautions. Concerning the PPE utilization, $89 \%$ of the study participants believe that using the PPE while accidents happen during the healthcare delivery procedure is mandatory. This finding is slightly better than a study from the governmental healthcare facilities of Addis Ababa (80\%) [40]. This difference might be attributed to the difference in the academic background of the study respondents, sampling technique and sample size between studies.

In the current study, an unacceptably low (57.4\%) proportion of the study participants had adequate practice score regarding safety precaution which is lower than a study conducted among the government healthcare facilities of Addis Ababa (66.1\%) [40]. The result is; however, more or less comparable to $54.2 \%$ and $60.5 \%$ studies from Bahir Dar and Wolaitta, respectively [31, 37]. Hand washing practice after patient contact/handling of infectious wastes is the most important safety precaution practice; however, in this study, only (55\%) of the HCPs studied were complied hand washing practice after patient contact/handle biologically hazardous substances. This finding is lower than a study from public health facilities of Mekelle in which about $61.5 \%$ of study participants always washed their hands [41]. With respect to injuries related to needle stick injuries, a year prevalence rate of needlestick injury (26.6\%) in this study was unacceptably high. Better findings $17.5 \%$ and $18.7 \%$ were obtained from different parts of Ethiopia [42, 43]. This result is; however, much lower than a study conducted among the governmental healthcare facilities of Addis Ababa (30\%) [40]. In this study changing gloves between patient contacts was $64.5 \%$ which is far lower than the previous study in Gondar university hospital (80.6\%) [27]. The practice of $\mathrm{HCPs}$ related to wearing gloves during risky procedures about $88.7 \%$ of the study participants, this study the is similar to the previous the studies in this area (88.7\%) [27].

\section{Conclusions}

Generally, the levels of knowledge, attitude, and practice scores among the HCPs were found to be low and there was a high prevalence of needlestick/sharp injuries. However, the use of PEP after potential exposures was very limited. Therefore, the hospital should ensure adequate and consistent supply of personal protective devices and other materials used for infection prevention and control. In addition, there should be awareness raising mechanism, including the provision of job aids and periodic training on proper hand washing, PEP administration protocols, and safe disposal of biologically hazardous wastes including evaluation of the trainees' practices through observation by trainers to assess their level of competency against minimum acceptable standards. In addition, HCPs should be committed to safety practices. Further, periodic and comprehensive studies should be conducted by including different types and levels of health facilities on a large scale.

\section{Limitations}

Data obtained from the study participants through selfreport were not cross-checked with their actual practices on the ground. Further, since the study was conducted in a single health facility, it could not be generalized at a national level.

\section{Supplementary information}

Supplementary information accompanies this paper at https://doi. org/10.1186/s13104-019-4605-5.

Additional file 1. Data collection tool.

Additional file 2: Table S1. Knowledge of the study participants about safety precaution at Gondar University referral hospital, Northwest Ethiopia, 2018.

\section{Abbreviations}

HCPs: healthcare professionals; HBV: hepatitis B virus; HCV: hepatitis C virus; HIV: human immune deficiency virus; PPE: personal protective equipment; SPSS: Statistical Package for Social Sciences. 


\section{Acknowledgements}

The authors would like to acknowledge Gondar University and Gondar University Referral Hospital. In addition, all data collectors and study participants were highly acknowledged.

\section{Authors' contributions}

TDY conceived the proposal. TDY and GBS provide training for the data collectors and all authors actively participated during the data collection. TDY and WA conducted the data analysis, interpretation, and write-up of the draft manuscript. WA and GBS revised and finalized the manuscript. All authors read and approved the final manuscript.

\section{Funding}

The study was fully granted by the University of Gondar and the organization have no any role during the study nor the final manuscript preparation.

\section{Availability of data and materials}

The data collection tool used in this study to collect data on knowledge, attitude, and practices among the HCPs is attached as an additional file.

\section{Ethics approval and consent to participate}

Ethical clearance and support letters were obtained from the Ethical Review Committee (ERC) of the School of Biomedical and Laboratory Sciences, University of Gondar. The support letter was submitted to the Gondar University referral hospital. Then, permission was obtained from the hospital director and department/section heads. Study participants were informed about the purpose and importance of the study through written informed concent before the data collection process. In addition, participants who were unwilling to take part in the study and those who need to quit their participation at any stage were informed to do so without any restriction.

\section{Consent for publication}

Not applicable.

\section{Competing interests}

The authors declare that they have no competing interests.

\section{Author details}

${ }^{1}$ Unit of Quality Assurance and Laboratory Management, School of Biomedical and Laboratory Sciences, College of Medicine and Health Sciences, University of Gondar, P. O. Box 196, Gondar, Ethiopia. ${ }^{2}$ Immunology and Molecular Biology Department, School of Biomedical and Laboratory Sciences, College of Medicine and Health Sciences, University of Gondar, P. O. Box 196, Gondar, Ethiopia. ${ }^{3}$ Microbiology Department, School of Biomedical and Laboratory Sciences, College of Medicine and Health Sciences, University of Gondar, P. O. Box 196, Gondar, Ethiopia.

Received: 18 April 2019 Accepted: 4 September 2019

Published online: 09 September 2019

\section{References}

1. Ogoina D, Pondei K, Adetunji B, Chima G, Isichei C, Gidado S. Knowledge, attitude and practice of standard precautions of infection control by hospital workers in two tertiary hospitals in Nigeria. J Infect Prev. 2015;16:16-22.

2. Allegranzi B, Pittet D. Role of hand hygiene in health-care associated infection prevention. J Hosp Infect. 2009;73:305-15.

3. Hilburn J, Hammond BS, Fendler EJ, Groziak PA. Use of alcohol hand sanitizer as an infection control strategy in an acute care facility. Am J Infect Control. 2003;31:109-16.

4. Sabbah I, Sabbah H, Sabbah S, Akoum H, Droubi N. Occupational exposures to blood and body fluids (BBF): assessment of knowledge, attitude and practice among health care workers in general hospitals in Lebanon. Health. 2013;5:70-8.

5. Kermode M, Jolley D, Langkham B, Thomas MS, Crofts N. Occupational exposure to blood and risk of bloodborne virus infection among health care workers in rural north India health care settings. Am J Infect Control. 2005:33:34-41.
6. Valim MD, Marziale MH, Richart-Martinez M, Sanjuan-Quiles A. Instruments for evaluating compliance with infection control practices and factors that affect it: an integrative review. J Clin Nurs. 2014;23:1502-19.

7. Goswami HM, Soni ST, Patel SM, Patel MK. A study on knowledge, attitude and practice of laboratory safety measures among para-medical staff of laboratory services. Natl J Community Med. 2011;2:470-3.

8. Nazir A, Kadiri S. An overview of hospital acquired infections and the role of microbiology laboratory. Int J Res Med Sci. 2014;2:21-7.

9. Vaz K, McGrowder D, Alexander R, Gordon L, Brown P, Irving R. Knowledge, awareness and compliance with universal precautions among health care workers at the University Hospital of the West Indies. Jamaica. Int J Occup Environ Med. 2010;1:171-81.

10. Federal Ministry of Health of Ethiopia. Infection prevention and patient safety-reference manual for service providers and managers in healthcare facilities of Ethiopia. 2nd ed. Addis Ababa: Federal Ministry of Health; 2012.

11. Trampuz A, Widmer AF. Hand hygiene: a frequently missed lifesaving opportunity during patient care. Mayo Clin Proc. 2004;79:109-16.

12. Akhter J, Al Johani S, Hammad L, Al Zahrani K. Laboratory work practices and occupational hazards among laboratory healthcare workers: a health and safety survey. J Pharm Biomed Sci. 2011;9:4.

13. Raka L, Mulliqi-Osmani G. Infection control in developing world. In: Infection control-updates. 2012.

14. Hutin Y, Hauri A, Chiarello L, Catlin M, Stilwell B, Ghebrehiwet T, et al. Best infection control practices for intradermal, subcutaneous, and intramuscular needle injections. Bull World Health Organ. 2003;81:491-500.

15. Pruss-Ustun A, Rapiti E, Hutin YJ. Estimation of the global burden of disease attributable to contaminated sharps injuries among health-care workers. Am J Ind Med. 2005;48:482-90.

16. Prüss-Üstün A, Rapiti E, Hutin Y. Sharps injuries: global burden of disease from sharps injuries to health-care workers. Geneva: World Health Organization; 2003.

17. Fashafsheh I, Ayed A, Eqtait F, Harazneh L. Knowledge and practice of nursing staff towards infection control measures in the Palestinian Hospitals. J Educ Pract. 2015:6:80-90.

18. Wondwossen K. Assessment of knowledge, attitude and practice towards occupational health and safety among medical laboratory personnel in selected governmental teaching hospitals of Ethiopia. Addis Ababa: AAU; 2015.

19. Sadoh WE, Fawole $A O$, Sadoh $A E$, Oladimeji $A O$, Sotiloye OS. Practice of universal precautions among healthcare workers. J Natl Med Assoc. 2006:98:722.

20. Amoran OE, Onwube OO. Infection control and practice of standard precautions among healthcare workers in Northern Nigeria. J Glob Infect Dis. 2013;5:156-63.

21. Ibrahim AA, Elshafie SS. Knowledge, awareness, and attitude regarding infection prevention and control among medical students: a call for educational intervention. Adv Med Educ Pract. 2016;7:505-10.

22. Allegranzi B, Nejad SB, Combescure C, Graafmans W, Attar H, Donaldson L, et al. Burden of endemic health-care-associated infection in developing countries: systematic review and meta-analysis. Lancet. 2011;377:228-41.

23. Fadeyi A, Fowotade A, Abiodun MO, Jimoh AK, Nwabuisi C, Desalu OO. Awareness and practice of safety precautions among healthcare workers in the laboratories of two public health facilities in Nigeria. Niger Postgrad Med J. 2011;18:146.

24. Kerity SH, Naji AB. Evaluation of healthcare workers' practices concerning infection control measures at primary health care centers. Int J Res Med Sci. 2017;1:63-8.

25. Adams J, Bartram J, Chartier Y. Essential environmental health standards in health care. Geneva: WHO; 2008.

26. Beyera GK, Beyen TK. Epidemiology of exposure to HIV/AIDS risky conditions in healthcare settings: the case of health facilities in Gondar City, Northwest Ethiopia. BMC Public Health. 2014;14:1283.

27. Haile TG, Engeda EH, Abdo AA. Compliance with standard precautions and associated factors among healthcare workers in Gondar University comprehensive specialized hospital, Northwest Ethiopia. J Environ Public Health. 2017. https://doi.org/10.1155/2017/2050635.

28. Tenna A, Stenehjem EA, Margoles L, Kacha E, Blumberg HM, Kempker RR. Infection control knowledge, attitudes, and practices among healthcare workers in Addis Ababa, Ethiopia. Infect Control Hosp Epidemiol. 2013:34:1289-96. 
29. Alemayehu R, Ahmed K, Sada O. Assessment of knowledge and practice on infection prevention among health care workers at Dessie Referral Hospital, Amhara Region, South Wollo Zone, North East Ethiopia. J Community Med Health Educ. 2016;6:487.

30. Ofonime EJ, Assi EA, Ibienebari JB, Ubokobong EH, Freda EA, Martin AO. Knowledge and practice of standard precautions among health care workers in a secondary facility in southern Nigeria. Int J Biomed Res. 2019;10:e5033.

31. Hussen S, Estifanos W, Melese E, Moga F. Knowledge, attitude and practice of infection prevention measures among health care workers in Wolaitta Sodo Otona Teaching and Referral Hospital. J Nurs Care. 2017;6:1-7.

32. Geberemariyam BS, Donka GM, Wordofa B. Assessment of knowledge and practices of healthcare workers towards infection prevention and associated factors in healthcare facilities of West Arsi District, Southeast Ethiopia: a facility-based cross-sectional study. Arch Public Health. 2018;76:69.

33. Gizaw GD, Alemu ZA, Kibret KT. Assessment of knowledge and practice of health workers towards tuberculosis infection control and associated factors in public health facilities of Addis Ababa, Ethiopia: a cross-sectional study. Archi Public Health. 2015;73:15.

34. Karmakar N, Datta SS, Datta A, Nag K, Tripura K, Bhattacharjee P. A cross sectional study on knowledge attitude and practice of biomedical waste management by healthcare personnel in a tertiary care hospital of Agartala. Natl J Res Community Med. 2016;5.

35. Alene KA, Adane AA, Yifiru S, Bitew BD, Adane A, Koye DN. Knowledge and practice of health workers about control and prevention of multidrug-resistant tuberculosis in referral hospitals, Ethiopia: a cross-sectional study. BMJ Open. 2019;9:e022948.

36. Yohannes T, Kassa G, Laelago T, Guracha E. Health-care workers' compliance with infection prevention guidelines and associated factors in Hadiya Zone, Southern Ethiopia: hospital based cross sectional study. Epidemiol Int J. 2019;3:000117.
37. Gulilat K, Tiruneh G. Assessment of knowledge, attitude and practice of healthcare workers on infection prevention in Health Institution Bahir Dar city administration. Sci J Public Health. 2014;2:384-93.

38. Desta M, Ayenew T, Sitotaw N, Tegegne N, Dires M, Getie M. Knowledge, practice and associated factors of infection prevention among healthcare workers in Debre Markos referral hospital, Northwest Ethiopia. BMC Health Serv Res. 2018;18:465.

39. Abdulraheem IS, Amodu MO, Saka MJ, Bolarinwa OA, Uthman MM. Knowledge, awareness and compliance with standard precautions among health workers in North Eastern Nigeria. J Community Med Health Educ. 2012;2:1-5.

40. Sahiledengle B, Gebresilassie A, Getahun T, Hiko D. Infection prevention practices and associated factors among healthcare workers in governmental healthcare facilities in Addis Ababa. Ethiop J Health Sci. 2018;28:177-86.

41. Gebresilassie A, Kumei A, Yemane D. Standard precautions practice among health care workers in public health facilities of Mekelle special zone, Northern Ethiopia. J Community Med Health Educ. 2014;4:286.

42. Dilie A, Amare D, Gualu T. Occupational exposure to needle stick and sharp injuries and associated factors among health care workers in Awi Zone, Amhara Regional State, Northwest Ethiopia. J Environ Public Health. 2017. https://doi.org/10.1155/2017/2438713.

43. Reda AA, Fisseha S, Mengistie B, Jean-Michel V. Standard precautions: occupational exposure and behavior of health care workers in Ethiopia. PLOS ONE. 2010;5:e14420.

\section{Publisher's Note}

Springer Nature remains neutral with regard to jurisdictional claims in published maps and institutional affiliations.
Ready to submit your research? Choose BMC and benefit from:

- fast, convenient online submission

- thorough peer review by experienced researchers in your field

- rapid publication on acceptance

- support for research data, including large and complex data types

- gold Open Access which fosters wider collaboration and increased citations

- maximum visibility for your research: over $100 \mathrm{M}$ website views per year

At BMC, research is always in progress.

Learn more biomedcentral.com/submissions 